\title{
David Oliver: Why force GP streaming on NHS emergency departments?
}

\author{
David Oliver consultant in geriatrics and general internal medicine
}

Berkshire

The government recently announced plans to expand GP streaming in emergency departments, after claims that it had reduced pressure on them. GP streaming was rolled out in 2017 when Simon Stevens, NHS chief executive, announced a plan to have it in place at all NHS hospitals with emergency departments. ${ }^{1}$ This would, he claimed, free up capacity in hospitals and cut overcrowding. Some $£ 100 \mathrm{~m}$ (€112m; \$125m) of capital expenditure was set aside to upgrade facilities, and the initiative was then incorporated into the NHS 10 year plan. $^{2}$ But what is GP streaming, and does it work?

Stevens picked out Luton and Dunstable Hospital Trust as an exemplar, after its emergency department showed dramatically improved performance against waiting time targets despite considerable local demand. ${ }^{1}$ GP streaming had been a key part of this very local improvement drive. So, what had Luton done?

The model was described by NHS Improvement as being open from 8 am to $11 \mathrm{pm}$, seven days a week. Triaging nurses in the main emergency department used a criteria checklist to direct patients to GPs co-located on the main hospital site. ${ }^{3}$

The focus was on lower acuity walking patients without chest pain, including those revisiting within 24 hours with the same condition. The triage nurse had the option of streaming patients to emergency department minors, majors, the resuscitation bay, or the GP centre, while GPs were able to refer directly to admitting specialties and 40-60\% of walking patients were streamed to GPs. This concept, with some local variation, is the template for the national adoption of GP streaming.

\section{The evidence}

The Royal College of Emergency Medicine has estimated that around $15 \%$ of attenders at major emergency departments might not be there if they had seen a GP in that 24 hour period. ${ }^{4} \mathrm{~A}$ study on emergency department use in Yorkshire estimated that $23 \%$ of adults attended for non-urgent reasons ${ }^{2}$ —and "primary care sensitive conditions" feature heavily among (especially older) adults attending emergency departments. ${ }^{5}$ So, there seems to be a rationale for trialling this approach.
As we know, local context is crucial in improvement initiatives, so what worked in Luton can't be assumed to work everywhere. The case mix will vary, as will the strength of existing primary care, so it's worth looking at the empirical evidence on what happens when these services are rolled out more widely. A 2015 systematic review of primary care services co-located in emergency departments found no overall evidence of improvements in process outcomes (such as admission/discharge rates or waiting times), effectiveness, or cost effectiveness. ${ }^{6}$ In some cases they were associated with increased demand and admission numbers.

In 2018 the National Institute for Health and Care Excellence reviewed emergency and acute medical care in over 16s and found no clear evidence for such models. ${ }^{7}$ A 2019 review found inconsistent terminology around primary care services in emergency departments, as numerous different models were put under the same umbrella. Any meaningful evaluation must be much clearer about defining the delivery model and not comparing apples and oranges. ${ }^{8}$

\section{Lack of beds}

Another concern is that putting GPs (if we can find them) into urgent care settings risks further depriving local primary care services, for which their training has been tailored. I'd suggest that doctors and nurses working in emergency and acute medical units are already skilled expert generalists, used to de-escalating and discharging patients and accepting managed risk. It's a big assumption that GPs would do this any better. And, although many walking patients do present to emergency departments with primary care sensitive problems, they generally wouldn't require admission.

Finally, the biggest problems facing major emergency departments-and which lead to overcrowding and long waits-are more to do with sicker patients requiring admission to beds that aren't there. This is due to a combination of low overall bed numbers and problems with flow, which are often caused by lack of capacity in community health and care services. Emergency medicine doctors have been saying this 
for some time. Yet NHS leadership focuses on diverting or preventing the less sick patients from attending hospitals, forcing models such as GP streaming on them instead of allowing locally appropriate solutions to flourish.

Let's listen to the people who do the job, understand it, and can tailor solutions to local circumstances.

Competing interests: See bmj.com/about-bmj/freelance-contributors.

Provenance and peer review: Commissioned; not externally peer reviewed.

1 National Health Executive. Integrated "streaming" service to be introduced in all hospitals by Christmas. 16 Mar 2017. http://www.nationalhealthexecutive.com/Health-Care-News/ integrated-streaming-service-to-be-introduced-in-all-hospitals-by-christmas.

2 Philip P. Blog: What does the long term plan mean for urgent and emergency care delivery? NHS England. 16 Sep 2019. https://www.england.nhs.uk/blog/what-does-the-long-termplan-mean-for-urgent-and-emergency-care-delivery/.
3 NHS Improvement. Seven day urgent care GP centre at Luton and Dunstable. https:// improvement nhs.uk/documents/118/7 day services - urgent care GP centre.pdf. 4 Full Fact. Are patients going to A\&E instead of GPs? 31 Jan 2017. https://fullfact.org/ health/are-patients-going-e-instead-gps/.

5 Ramlakhan S, Mason S, O'Keeffe C, Ramtahal A, Ablard S. Primary care services located with EDs: a review of effectiveness. Emerg Med J 2016;33:495-503. https://www.ncbi. nlm.nih.gov/pubmed/27068868. 10.1136/emermed-2015-204900 27068868

6 Cowling TE, Soljak MA, Bell D, Majeed A. Emergency hospital admissions via accident and emergency departments in England: time trend, conceptual framework and policy implications. J R Soc Med 2014;107:432-8. https://journals.sagepub.com/doi/full/10.1177/ 0141076814542669. 10.1177/0141076814542669 25377736

7 National Institute for Health and Care Excellence. Chapter 18-Minor injury unit, urgent care centre or walk-in centre. Emergency and acute medical care in over 16s: service delivery and organisation. NICE guideline 94. Mar 2018. https://www.nice.org.uk/guidance/ ng94/evidence/18minor-injury-unit-urgent-care-centre-or-walkin-centre-pdf-172397464605.

8 Cooper A, Edwards M, Brandling J, etal . Taxonomy of the form and function of primary care services in or alongside emergency departments: concepts paper. Emerg Med J 2019;36:625-30. https://emj.bmj.com/content/36/10/625

10.1136/emermed-2018-208305 31494576

Published by the BMJ Publishing Group Limited. For permission to use (where not already granted under a licence) please go to http://group.bmj.com/group/rights-licensing/ permissions 